\title{
Fear of Statistics among TEFL Postgraduate Students
}

\author{
Seyed Mohammad Reza Amirian a *(D), Saeed Abbasi-Sosfadi a \\ ${ }^{a}$ Department of English Language, Hakim Sabzevari University, Sabzevar, Iran
}

\begin{tabular}{l|l|l} 
Received 18 August 2020 & Received in revised form 17 October 2020 & Accepted 25 October 2020
\end{tabular} APA Citation: Amirian, S.M.R., \& Abbasi-Sosfadi, S. (2021). Fear of statistics among TEFL postgraduate students.
Eurasian Journal of Applied Linguistics, 7(1), 202-221.

Doi: $10.32601 /$ ejal.911253

\begin{abstract}
Although statistics is an important compulsory course in a wide variety of disciplines, the vast majority of students including TEFL postgraduate students find it frightening and difficult to understand, and thus suffer from underachievement. As a result, a specific kind of anxiety called statistical anxiety emerges that requires immediate attention. To date, a large and growing body of research has focused on exploring different aspects and dimensions of statistics that produce fear and tension. However, the problem of fear of statistics amongst TEFL postgraduate students has received scant attention in the literature. In this study, attempts are made to assess and describe the areas of anxiety that TEFL postgraduate students experience during a statistics course. To this end, the present study employed a descriptive research design, i.e., survey research. First, a statistical anxiety questionnaire, which reflects three correlated dimensions of statistical anxiety including Examination Anxiety, Asking for Help Anxiety, and Interpretation Anxiety, was distributed among 72 TEFL postgraduate students. Then, interview sessions were held with 10 participants for the purpose of further exploration of the participants' responses to the questionnaire items. Analysis revealed that examination anxiety has the highest frequency among other subscales, while the lowest frequency belongs to asking for help anxiety. These descriptive results together with the conceptualization of participants' perspectives regarding their major concerns in statistics have clear implications for statistics teachers, course developers, policy makers, and TEFL postgraduate students.
\end{abstract}

(C) 2021 EJAL \& the Authors. Published by Eurasian Journal of Applied Linguistics (EJAL). This is an open-access article distributed under the terms and conditions of the Creative Commons Attribution license (CC BY-NC-ND) (http://creativecommons.org/licenses/by-nc-nd/4.0/).

Keywords: Statistical Anxiety; TEFL; Examination Anxiety; Asking for Help Anxiety; Interpretation Anxiety

\section{Introduction}

Due to the increasing need for comprehending and conducting statistical techniques in a wide variety of disciplines, taking a statistics course has become compulsory in almost all universities for students (Onwuegbuzie \& Wilson, 2003). In other words, learning these subjects is of vital importance for academic and professional development of university students. That is, in order to be able to carry out

\footnotetext{
* Corresponding author. Tel.: +98-915-157-8563

E-mail address: sm.amirian@hsu.ac.ir

http://dx.doi.org/10.32601/ejal.911253
} 
quantitative studies, and understand and interpret numerical research findings, it is imperative that students in different disciplines master statistical courses. Nevertheless, a vast majority of students whose background knowledge in statistics is not strong enough find statistics-related courses frightening and even awkward to deal with or grasp. Consequently, a special kind of anxiety, which is specific to lack of statistical knowledge, would be inevitable, and thus becomes a major problem.

According to Zeidner (1990) statistics anxiety is defined as:

"a performance characterized by extensive worry, intrusive thoughts, mental disorganization, tension, and physiological arousal ...when exposed to statistics content, problems, instructional situations, or evaluative contexts, and is commonly claimed to debilitate performance in a wide variety of academic situations by interfering with the manipulation of statistics data and solution of statistics problems “(p. 319).

Put it simply, statistics anxiety refers to a particular type of panic that students generally experience when they attempt to deal with statistics-related courses and contents. In some special fields of study such as psychology, education, or sociology, since students are less interested in numbers and numerical relationships, statistics is often undervalued (Ruggeri, Dempster, Hanna, \& Cleary, 2008). Hence, as they are provided with statistical matters, they are more likely to be stressed out coping with the course (Onwuegbuzie, 2004; Onwuegbuzie \& Wilson, 2003; Druggeri et al., 2008). Indeed, statistics has been reported as the most anxiety-provoking course for many students (Blalock, 1987; Caine et al., 1978; Gaydosh, 1990; Lundgren \& Fawcett, 1980; Schacht \& Stewart, 1990, 1991; Zeidner, 1991). This has made quantitative and statistics classes terribly negative and irritating (Onwuegbuzie, 1997). For that reason, students often prefer to postpone and procrastinate taking statistics-related credits, and feel nervous and anxious during quantitative methods courses (Onwuegbuzie, 1997; Robert \& Bilderback, 1980).

The above-mentioned tension is far more palpable in human and social sciences where there is less room for practicing numbers. Decades ago, applied linguistics in general and second language acquisition in particular used to be less concerned with the practical application of technical knowledge of statistics. However, owing to a substantial increase in applying interdisciplinary research in the field of applied linguistics, statistics has gained explosive growth among researchers and practitioners. In other words, interdisciplinary approach to research has encouraged diversity in research methods, each requires a specific statistical technique. This has led to a growing need to deal with statistics and obtain sound statistical knowledge (Comanaru, 2014, Pica, 2003). The literature on statistical literacy clearly illustrates how crucial statistical knowledge is for applied linguistics research (Lazaraton, 1987; Loewen et al., 2014; Gonulal, Loewen, \& Plonsky, 2017). Through developing statistical knowledge, EFL/ESL researchers can easily summarize the collected data from samples and then generalize their findings to a population of interest (Scholfield, 1991), which is the main objective in quantitative research methods. However, the 
problem is that factors such as insufficient statistical background, confidence, knowledge, and experience have made statistics too complex and confusing to be understood. That is why TEFL postgraduate students are a particular group of students who severely suffer from inability of conducting statistical works.

Not only do students come across such a major challenge and a formidable obstacle, but teachers also become frustrated of encouraging students to learn what they have not been genetically wired for. In other words, learners' exasperation adds to the complexity of statistics teaching. Taking this educational obstacle into account, it is essential that the major anxiety provoking areas of statistics be unveiled so that further attention could be paid to them in order to come up with workable solutions to students' problems in quantitative methods. This gap is intended to be filled in the present study. The beneficial consequences of this work would enable and empower TEFL postgraduate students to identify their weaknesses in doing and interpreting quantitative works rather than escaping from the field, and teachers to revise their teaching methods and materials.

\subsection{Explore importance of the problem}

The findings of previous studies evidence the fact that in spite of the extensive use and application of quantitative research designs in EFL/ESL studies over the past years, researchers do not feel much confident about applying sophisticated statistical analysis techniques. The situation is rather worse for those postgraduate students who do not possess sufficient statistical knowledge and experience. Consequently, a statistics-related anxiety that negatively influences students' performances and attitudes towards statistics emerges. Therefore, the fact that how fearful statistics can be, particularly for those who have not obtained a good knowledge, is now clearer than ever before. This fear has its major roots in the apparent lack of confidence in using and interpreting statistical works (Loewen et al., 2014; Gonulal, Loewen, \& Plonsky, 2017). Thus, the purpose of this investigation is to shed more light on the nature and kinds of statistics-related anxiety among university students and uncover the roots of fear of statistics in postgraduate students of TEFL.

\subsection{Describe relevant scholarship}

The term statistical anxiety tends to be used to refer to a specific situation in which statistics course produces tension, fear, and nervousness (e.g., Macher et al., 2015). This type of anxiety is so common that nearly 80 percent of students in social and behavioral sciences experience it (Onwuegbuzie \& Wilson, 2003). With that being said, the existing literature on statistical anxiety is extensive and focuses particularly on this issue. For instance, Cruise, Cash, and Bolton (1985) believed that statistics anxiety is a multidimensional construct which is composed of six main anxiety types: 1) Interpretation Anxiety, which involves the stress derived from interpreting statistical data; 2) Test and Class Anxiety, which refers to participation in statistics class and exam; 3) Fear of Asking for Help that emerge when asking for help during a 
statistics lesson; 4) Worth of Statistics, which indicates students' perspectives regarding the relevance of statistics; 5) Computation Self-Concept, which refers to students' self-confidence in understanding and dealing with statistics; and finally 6) Fear of Statistics Teachers, which reflects the anxiety comes from the teachers.

Moreover, antecedents of statistics anxiety have been classified as situational, dispositional, and environmental (Baloglu, 2004; Onwuegbuzie \& Wilson, 2003). Situational antecedents refer to the attitudes and experiences towards statistics and mathematics (Baloğlu, 2004; Bell, 2005; DeVaney, 2017). Academic self-concept and students' interest are important examples of situational antecedents of statistics anxiety (Benson, 1989; Jones et al., 2011; Krapp, 2005; Pintrich \& DeGroot, 1990; Zeidner, 1991). Dispositional antecedents reflect people's personality traits like procrastination (Onwuegbuzie, 2004). Environmental antecedents refer to some background variables such as age, gender, and prior mathematics experience that have been extensively studied in numerous studies reporting divergent results.

As far as age is concerned, previous studies reported inconclusive results. For instance, it was shown in a study that older learners are more statistically anxious than their younger counterparts (Bell, 2003). On the contrary, age in another study was found to make no difference in the level of anxiety (Bui \& Alfaro, 2011). Apart from age, gender differences in statistics anxiety have been investigated in a number of different studies, which illustrated that, irrespective of their field of study, females are more likely to be statistically stressed out than males (Benson, 1989; Benson \& Bandalos, 1989). What is more, while some studies reported that there are no gender differences in statistics anxiety (Baloğlu, 2003; Bui \& Alfaro, 2011; Hsiao \& Chiang, 2011), others highlighted such differences (Baloğlu, Deniz, \& Kesici, 2011; RodarteLuna \& Sherry, 2008).

Furthermore, prior statistics and mathematical knowledge and skills are found to be significantly correlated with the level of statistics anxiety that learners may experience (Zeidner, 1991; Trimarco, 1997). On the whole, the more prolonged exposure students have to statistics and mathematics, the less anxious they are when studying, interpreting, and taking exams in the field. Similarly, some studies found that the amount of anxiety in students with little or no statistical background is far more than those who already took courses in numerical sciences (Benson, 1989; Huns ley, 1987; Morris, Kellaway, \& Smith, 1978; Sutarso, 1992). They also indicated that as mathematic anxiety rises, statistical achievement reduces drastically. This issue has also been addressed in the work of Malik (2015). The findings of self-report scale regarding the factors contributing to statistics anxiety showed that students with a good numerical history tend to be less nervous. However, those who have problems understanding the language of statistics feel more anxiety symptoms.

In addition, the relationship between statistics anxiety and achievement as well as performance have been dealt with in several studies applying multivariate analyses (Fitzgerald, 1996; Onwuegbuzie, 2003; Onwuegbuzie \& Seaman, 1995). It is clearly evident from the reports of the aforementioned studies that nervous students are 
more likely to fail (Fitzgerald, 1996). In their Structural Equation Analysis (SEM) based path analysis, Onwuegbuzie (2003) reported a significant relationship between anxiety and performance. Likewise, the association between anxiety and test result in a study by Onwuegbuzie and Seaman (1995) was found as meaningful and significant.

Another crucial factor that may affect the level of statistics anxiety is perfectionism (Onwuegbuzie \& Daley, 1999). It has been reported that as long as students attempt to maintain idealistic standards, they are more anxious and nervous compared to those who are less perfectionist in terms of interpretation, test and class, and asking for help anxiety. Besides perfectionism, students' self-image of their ability to comprehend statistics and their level of self-esteem were found to have significant contribution to statistics anxiety (Zeidner, 1991).

As a solution, Bridges et al. (1998), in a quasi-experimental study, attempted to see if statistics anxiety might be reduced by spreading the course across the degree instead of presenting it as a one-shot design course. The findings of their study showed that the intervention was successful in understanding quantitative reasoning and lowering anxiety. In a similar vein, Onwuegbuzie et al. (2010) debated that presenting quantitative methods alone raises the level of anxiety. Thus, what is evident is that an alternative approach would help in reducing the statistics-related anxiety. The very same perspective has been verified by other studies too (Gorard, 2015; Payne \& Williams, 2011). In a quite different vein, Williams et al. (2015) came to a different conclusion with regard to the presentation of quantitative method on a substantive unit. According to them, this kind of course can lead to negative consequences.

Turning now to the necessity of using statistics in quantitative research designs in the field of applied linguistics, different scholars have investigated the extent to which attention has been paid to such designs (Lazaraton, 2000; Lazaraton, 2005; Loewen \& Gass, 2009; Plonsky \& Gass, 2011; Cunnings, 2012; Plonsky, 2013). For instance, during a period of seven years from 1991 to 1997, 90 percent of the published investigations in four leading journals were found to be quantitative (Lazaraton, 2000). Years later, an increase in the strong tendency to incorporate statistics into research designs was verified again (Lazaraton, 2005; Loewen \& Gass, 2009). However, there existed some degrees of inconsistency regarding the application of more advanced statistical techniques such as structural equation modeling (Loewen \& Gass, 2009; Cunnings, 2012; Plonsky \& Gass, 2011; Plonsky, 2013). In a recent study, Khany and Tazik (2019) reported that, among other things, descriptive statistics and ANOVA are favored. Similarly, the popularity of ANOVA-related techniques was already discussed by Lazaraton (2005). It is important to know that instances of weak quantitative research design are highlighted in the literature bearing in mind the problem of insufficient statistical knowledge (Plonsky, 2013).

In an investigation to assess the statistical knowledge of applied linguistics and second language acquisition researchers, Loewen et al. (2019) found that, despite their mastery over the basic statistical concepts, researchers of the field possess lower 
level of knowledge about more advanced statistical topics. In addition, experience in taking statistics course as well as making use of different statistics textbooks are found as the predicators of in-depth statistical knowledge. Likewise, lack of interest on the part of researchers to apply advanced statistical techniques such as factor analysis and regression analysis was highlighted by Lindstromberg (2016) where some experimental studies of Language Teaching Research journal were examined. The study showed a marked tendency for traditional statistical methods.

In summary, it has been shown from this review that no previous study has ever considered TEFL postgraduates' statistical anxiety. It is still unknown to what extent these students are anxious in using statistics. Moreover, very little is currently known about the most anxiety provoking areas of statistics for this particular group of students. This paper attempts to fill the stated gaps by describing the frequency of TEFL postgraduate students' statistical anxiety. To this end, a statistical anxiety scale that is composed of 24 items designed by Vigil-Colet, Lorenzo-Seva, and Condon (2008) was used. The underlying factors are three related subscales from the overall scale of statistical anxiety including Examination Anxiety, Asking for Help Anxiety and Interpretation Anxiety. All survey questions utilized a 5-point Likert scale and designed to ascertain the participants' fear of statistics. After the administration of the questionnaire, semi-structured interview sessions were held with 10 participants to shed more light on their perception of statistical anxiety by asking open-ended questions. The research question "To what extent TEFL postgraduate students feel anxious in applying statistics?" directed the study. For the interview sessions, some questions related to each of the three sub-scales were formulated prior to the formal sessions.

\section{Method}

\subsection{Participants}

Since this study aims at describing the anxiety that TEFL students experience during a statistics course, participants were recruited from postgraduate programs where statistics is a core subject and a prerequisite for other courses. A total of 72 M.A. and Ph.D. students (31 M.A. and 41 Ph.D.) who had had the experience of taking a statistics course were selected through convenience sampling from different institutions and were given the questionnaire. Of the 72 participants, 10 were selected to take part in interview sessions for further investigations of their responses to the questionnaire items and explication of their views more precisely. The criteria for selecting interview participants were their willingness to volunteer, availability, and ease of accessibility at the time of interview sessions (Dörnyei, 2007). Participants were aged between 24 and $45($ mean $=29.97)$, and 54 out of 72 were female $(75 \%)$, while $18(25 \%)$ were male.

\subsection{Instrumentation}


To get cognizant of the level of TEFL postgraduate students' statistical anxiety, both electronic and paper questionnaires were sent to the participants to be filled. The questionnaire employed in the present study is a 24 -item statistical anxiety scale, which assesses students' fear they feel in a course of statistics developed and validated by Vigil-Colet, Lorenzo-Seva, and Condon (2008). The inventory has three main dimensions including Examination Anxiety, Asking for Help Anxiety, and Interpretation Anxiety that are related subscales from the overall scale of statistical anxiety. There are 8 corresponding items for each subscale. Each item is a positive sentence describing a typical situation that students might experience. Respondents can indicate their level of anxiety using a five-point scale ranging from $<<$ no anxiety $>>$ (1) to $<<$ considerable anxiety $>>$ (5). The reliability index of the overall scale is .911. To validate the instrument, a correlation between general measures of anxiety (Trait anxiety and Neuroticism) and the scores on the subscales as well as the overall scale was computed. The results verified the relation between subscales and overall scale and participants' anxiety. In order to gather some additional information as corroborative evidence, semi-structured interviews were conducted with 10 participants in which open-ended questions related to each sub-scale were asked. Each of the three sub-scales was chosen as an area of interest and a set of corresponding questions were formulated prior to interview sessions. This helped us to observe the participants and ask them to explain the meanings in order to reveal what is important to understand about the phenomenon under scrutiny. During interview sessions, questions were presented to the interviewees and their responses were audio recorded for further analysis.

\subsection{Data collection}

In the interest of exploring how fearful and anxious students of TEFL are when taking statistics course, the present study employed a descriptive method, i.e., survey research. Given the descriptive not inferential nature of this study, a nonexperimental quantitative method in which the relationship between the variables is sought without being manipulated was required (Ary et al., 2013). A survey research was utilized to describe a possible association between individuals' educational field and their attitude towards statistics. The two major instruments for gathering data in survey studies are generally questionnaire and interview, which were employed in the present study to both quantitatively and qualitatively address the issue of statistical anxiety among TEFL postgraduate students.

It is pertinent to note that researchers do not look for causal inferences by surveys, but rather they are merely concerned with the description of how variables are distributed among a group of individuals (Ary et al., 2013). Since it is not always feasible to study very large population, researchers can select sample survey, i.e., studying only a portion of the population. Of the survey research types according to the time dimension, this study follows a cross-sectional method to gather data at one point in time. The benefit of this survey type is that it helps the researchers to collect the necessary data quickly and inexpensively. 


\subsection{Data analysis}

Since both quantitative and qualitative data were gathered in the present survey research, a combination of both approaches was used in the data analysis. Quantitative data analysis was carried out using SPSS, version 24. Once the data from the respondents were imported and data screening was performed, we started the analysis by running descriptive statistics including frequencies and descriptives in that the major purpose of this study was to understand if TEFL students experience anxiety during a statistics course rather than comparing groups. As explained earlier, the questionnaire utilized in this study is three dimensional. Therefore, separate frequency and descriptive statistics were performed for each subscale respectively apart from the preliminary analyses for individual items as well as the sum of the items for each single respondent.

For qualitative data analysis, the audio-recorded interview sessions were transcribed and analyzed line by line following the principles of qualitative data analysis in order to extract the relevant explanations of the participants' responses about their choices on questionnaire items. This step was followed by member checking to ensure the credibility of the extracted explanations, and elicit feedback from the participants about the findings. Moreover, to enhance the dependability of the conclusions, interviewees from different universities were selected for participation. The qualitative data analysis was performed in three stages: 1) familiarizing and organizing, 2) coding and reducing, and 3) interpreting and representing (Ary et al., 2013).

\section{Results}

The findings of this survey study are presented in two parts. The first part represents a set of numerical tables reporting the descriptive results regarding the areas of statistics that produce fear and tension for TEFL postgraduate students. The second part deals with students' perception of anxiety in each of the three sub-scales of the questionnaire. These qualitative findings are shown in table 5 .

\subsection{Part 1}

To assess TEFL postgraduate students' fear of statistics, statistical anxiety scale was used. Respondents were asked to indicate their level of anxiety in any given situation represented by an item using a 5-point Likert scale, ranging from "No anxiety" (1) to "Considerable anxiety" (5). As explained earlier, the questionnaire reflects three correlated dimensions, which are subscales of the overall scale of statistical anxiety.

Table 1: Descriptive statistics for the whole scale and the related subscales 


\begin{tabular}{llllll}
\hline & $\mathrm{N}$ & Minimum & Maximum & Mean & Std. Deviation \\
\hline Sum & 72 & 33.00 & 101.00 & 64.13 & 15.46 \\
Exam Sum & 72 & 13.00 & 40.00 & 28.27 & 6.86 \\
Interpretation Sum & 72 & 9.00 & 34.00 & 18.88 & 5.89 \\
Ask Sum & 72 & 8.00 & 38.00 & 16.97 & 7.11 \\
Valid N (listwise) & 72 & & & & \\
\hline
\end{tabular}

Table 1 provides an overview of the descriptive statistics for the questionnaire as a whole (i.e., sum) as well as the three related subscales. Exam-sum shows the sum of 8 items belong to examination anxiety, interpretation-sum indicates the sum of 8 items related to interpretation anxiety, and ask-sum represents the sum of 8 items of the asking for help anxiety. It is apparent from the table that the mean score for the sum of the items for all respondents is 64.13 . The table also reports that the examination anxiety subscale has the highest mean score of 28.27 among other subscales, while ask for help anxiety mean score is 16.97 , which is the lowest. The mean score for the interpretation anxiety subscale is 18.88 .

Table 2: Descriptive statistics for individual Items of the questionnaire

\begin{tabular}{|c|c|c|c|}
\hline & $\mathrm{N}$ & Mean & Std. Deviation \\
\hline$\overline{\text { Exam1 }}$ & 72 & 2.93 & 1.16 \\
\hline Interpretation 1 & 72 & 2.54 & 1.08 \\
\hline Ask1 & 72 & 2.31 & 1.21 \\
\hline Exam2 & 72 & 3.90 & 1.07 \\
\hline Ask2 & 72 & 2.06 & 1.17 \\
\hline Interpretation 2 & 72 & 2.25 & 1.11 \\
\hline Ask3 & 72 & 2.10 & 1.09 \\
\hline Interpretation 3 & 72 & 2.56 & 1.12 \\
\hline Exam3 & 72 & 3.40 & 1.17 \\
\hline Interpretation 4 & 72 & 2.06 & 1.03 \\
\hline Exam4 & 72 & 3.10 & 1.37 \\
\hline Ask4 & 72 & 2.13 & 1.15 \\
\hline Exam5 & 72 & 3.71 & 1.01 \\
\hline Exam6 & 72 & 3.38 & 1.16 \\
\hline Exam7 & 72 & 3.96 & 1.16 \\
\hline Interpretation 5 & 72 & 1.93 & .93 \\
\hline Ask5 & 72 & 1.97 & .96 \\
\hline Interpretation 6 & 72 & 2.49 & 1.06 \\
\hline Interpretation 7 & 72 & 2.68 & 1.34 \\
\hline Exam8 & 72 & 3.90 & 1.10 \\
\hline Ask6 & 72 & 2.24 & 1.00 \\
\hline Interpretation 8 & 72 & 2.25 & 1.11 \\
\hline Ask7 & 72 & 2.29 & 1.27 \\
\hline Ask 8 & 72 & 1.89 & 1.09 \\
\hline Valid N (listwise) & 72 & & \\
\hline
\end{tabular}


Table 2 illustrates the descriptive statistics for each individual item of the questionnaire. The abbreviated forms represented in the table correspond precisely to the three sub-scales mentioned earlier. Of the 24 items, the highest mean score is reported for item 15 (i.e., exam 7: realizing, just before you go into the exam, that I have not prepared a particular exercise), which is related to the examination anxiety subscale $($ mean $=3.96)$.

Table 3: Frequency of Item 15 with the highest number of Considerable Anxiety

\begin{tabular}{lllll}
\hline & Frequency & Percent & Valid Percent & $\begin{array}{l}\text { Cumulative } \\
\text { Percent }\end{array}$ \\
\hline No Anxiety & 3 & 4.2 & 4.2 & 4.2 \\
Little Anxiety & 6 & 8.3 & 8.3 & 12.5 \\
Moderate Anxiety & 14 & 19.4 & 19.4 & 31.9 \\
High Anxiety & 17 & 23.6 & 23.6 & 55.6 \\
Considerable Anxiety & 32 & 44.4 & 44.4 & 100.0 \\
\hline Total & 72 & 100.0 & 100.0 & \\
\hline
\end{tabular}

The highest number of responses to 'considerable anxiety' belongs to the same item which is 32 (see Table 3). The lowest mean score is related to item 24 (i.e., ask8: asking a private teacher to tell me how to do an exercise), which belongs to ask for help anxiety subscale $($ mean $=1.89$ ). This item also represents the highest frequency of 34 respondents for 'no anxiety' (see Table 4). It is worthy of note that 'considerable anxiety' has the lowest frequency in item 16 (i.e., interpretation 5: copying a mathematical demonstration from the blackboard while the teacher is explaining it) with no respondent marking it. The lowest frequency for 'no anxiety' is reported for item 20 (i.e., exam 8: going to a statistics exam without having had enough time to revise), which is again related to examination anxiety dimension (frequency $=1$ ).

Table 4: Frequency of Item 24 with the highest number of No Anxiety

\begin{tabular}{lllll}
\hline & Frequency & Percent & Valid Percent & $\begin{array}{l}\text { Cumulative } \\
\text { Percent }\end{array}$ \\
\hline No Anxiety & 34 & 47.2 & 47.2 & 47.2 \\
Little Anxiety & 23 & 31.9 & 31.9 & 79.2 \\
Moderate Anxiety & 6 & 8.3 & 8.3 & 87.5 \\
High Anxiety & 7 & 9.7 & 9.7 & 97.2 \\
Considerable Anxiety & 2 & 2.8 & 2.8 & 100.0 \\
\hline Total & 72 & 100.0 & 100.0 & \\
\hline
\end{tabular}

\subsection{Part 2}


As stated earlier, semi-structured interviews in which participants were given a set of open-ended questions related to each sub-scale were conducted for further elaboration of participants' responses to the questionnaire items. The three sub-scales of 'Examination Anxiety', 'Interpretation Anxiety', and 'Asking for Help Anxiety' were utilized as organizational categories that had been established prior to qualitative data collection (Ary et al., 2013). The raw data related to each sub-scale were read and reread several times and coded inductively through constant comparison of units of meaning which led to the development of meaningful concepts. These categories together with their related codes are represented in table 5.

Table 5. Organizational categories and the related codes.

\begin{tabular}{lll}
\hline Examination Anxiety & Interpretation Anxiety & Asking for Help Anxiety \\
\hline & & \\
Exam culture & Insufficient statistical background & Teachers' emotional support \\
Course complexities & Lack of procedural knowledge & \\
\hline
\end{tabular}

Having administered a statistical anxiety questionnaire, it was found that, among other things, much of the fear on the part of TEFL students regarding statistics has to do with examination anxiety. That is to say, students are more likely to feel anxious during exam time. This finding was strongly confirmed by the qualitative data. Analysis of participants' perspectives revealed Exam culture and Course complexities as two major sources of anxiety during statistics exam time. In a test-dominated context of Iran where exam culture is so strong, this finding is not unexpected. For Iranian students, success in exams is paramount. Therefore, their level of anxiety increases dramatically when they realize that their weaknesses in statistics may negatively affect their test scores. Talking about this proposition, one interviewee argued:

I personally don't have any problem with statistics since I have a good understanding of it and I enjoy dealing with issues like finding a right statistical technique or interpreting a table. However, it is always frightening to apply statistical knowledge at the time of exam because a small mistake can decrease your score to a great extent.

Another interviewee, when asked about examination anxiety, said:

During the semester, I am less anxious since I can count on my peers and instructor's support in case of difficulty, but in an exam session, I am supposed to rely on my own statistics knowledge. I can't imagine what happens if I don't get a problem right!

A possible explanation for this might be that since educational system puts a great emphasis on exam success, students have come to be too idealistic about their statistics scores. Therefore, part of their statistical anxiety is affected by their perfectionist tendency (Onwuegbuzie \& Daley, 1999). Another possible explanation for 
this exam-related anxiety resides in the complexities arise from the large volume of statistical topics covered in one single course. Talking about this issue an interviewee said:

As a student who really finds statistics tough and complicated to learn, I personally believe we do need more sessions on statistical topics beside our research courses! Especially when there is more than one source coupled with statistical complexities. Studying bulky books and numerous articles that contain statistics for exam is a nightmare for me and I'm afraid of not being able to practice all of them before going to exam.

Another finding of the present study was that interpretation anxiety accounts for almost 19 percent of TEFL postgraduates' statistical anxiety. Constant comparison of students' responses related to their perception of interpretation anxiety indicated Insufficient statistical background and Lack of procedural knowledge as two recurring concepts. Students are quite nervous in trying to understand the statistical explanations and make sense of them. According to students' elaboration in interview sessions, part of this fear is due to insufficient statistical background. For example, one individual stated:

In statistics class, I really feel disappointed when I see my classmates can easily understand and interpret tables and problems. I think I have difficulty understanding statistics because I don't have a theoretically sound background in mathematics. I have studied human sciences and unfortunately, I don't have a statistical mind.

Another participant alluded to the same problem and commented:

Many of my friends and I come from backgrounds irrelevant to statistics, and here, we are bombarded with innumerable sources which are painstakingly hard to manage. So, I always have butterflies in my stomach when I'm exposed to tables full of numbers.

This finding broadly supports the work of other studies in this area linking prior statistical and mathematical knowledge with students' level of anxiety and (Benson, 1989; Huns ley, 1987; Morris, Kellaway, \& Smith, 1978; Sutarso, 1992; Trimarco, 1997; Zeidner, 1991). Besides statistical background, students believe that lack of practice negatively influences their confidence in interpreting and dealing with statistical tasks. Supporting this point an interviewee said:

Unfortunately, much of the knowledge we gain in statistics is theoretical. Class time is mainly devoted to the discussion of the theoretical underpinnings of endless statistical procedures that we memorize but can't use in practice. I'd rather not be a volunteer for interpreting a table since I think my theoretical knowledge doesn't lead to success in practice.

Asking for help anxiety is found to be the least stressful dimension of statistical anxiety with one item demonstrating the highest frequency for 'no anxiety' (see Table 4). A recurrent theme in the interviews was a sense amongst interviewees that they are less apprehensive about their statistical weaknesses in situations where they need the instructors' help because there is no risk of losing a score or being judged. 
This common belief is conceptualized as Teachers' emotional support, which is a very important concept in this category. In this regard, one informant reported that:

The most carefree times during a statistics course are when I ask my teacher for help because I don't need to count on my knowledge and be worried about if I am wrong.

In addition, the emotional support that a teacher gives can be very influential in lowering the level of statistical anxiety. Commenting on emotional support, one of the interviewees said:

When I am praised by my statistics teacher, I have a better feeling and I am more confident to exercise my own judgment. Even when I have difficulty understanding something, asking the teacher for help really reduces my inner tension. It is a good feeling to know that the teacher is available.

What is more, statistics teachers play a determining role in making students nervous. If teachers neglect students' questions and weaknesses, not only are learners fed up with the whole course, but they are also more afraid of working with statisticrelated topics. As one interviewee put it:

For me asking for help is as anxious and fearful as examinations and interpretation. Unfortunately, our teacher is so intimidating that nobody dares to ask any question. He doesn't care about our insufficient statistical background at all. We are almost always supposed to understand everything without ever being allowed to make mistakes. Asking him for help is really annoying and I am really afraid of our final exam.

It is possible, therefore, that teachers add to the level of anxiety students experience in examinations.

\section{Discussion and conclusions}

The main goal of the current study was to assess and describe the anxiety that TEFL postgraduate students may experience during their statistics course. The study has shown that, generally, anxiety exists among students of TEFL. More specifically, this research has shown that students feel more anxious about statistics when they are tested. Analysis of participants' perspectives in interview sessions revealed that examination anxiety is not merely the matter of an academic subject like statistics itself; instead, it is the matter of fear of exam. Due largely to the exam culture in the educational context of Iran, students are always anxious during exam time, irrespective of what they are going to be tested on. Therefore, it is not possible to clearly distinguish between the sources of anxiety. This would be a fruitful area for further work as this study lacks empirical findings in this regard. The evidence from this study also suggests that students have complaint about the large volume of statistical sources that must be covered in a short period as studying them for exam brings about high level of statistical anxiety. This finding agrees with the results of other studies, in which extending quantitative courses is recommended (Bridges et al., 1998; Onwuegbuzie et al, 2010). An implication of this is possibly that faculty 
members and course designers plan for a more reasonable amount of materials during a single course or at least dedicate a limited amount for exam. However, further research could usefully investigate how it might be effective in reducing examination anxiety.

Another significant finding of this study, which was consistent with earlier research, was that lack of statistical background leads to a high degree of anxiety in interpreting and analyzing statistical works. This information can be used to develop targeted interventions aiming at building and developing statistical background prior to students' entrance to postgraduate programs. Furthermore, it has been found that pure theoretical knowledge does not help students to overcome their statistical problems. In other words, lack of sufficient guided and controlled statistical practice is one of the major sources of anxiety. A reasonable approach to tackle this issue could be to maintain a balance between students' declarative knowledge of statistics and their ability to apply procedural knowledge. Further work is needed to fully understand the implications of helping students realize what a bit of statistical theory has for practice and its effects on lowering anxiety. The data in the present study also provide the field with striking implications regarding the role of teachers in lowering the level of students' statistical anxiety. Anxiety, as an affective factor, is heavily dependent upon the nature of the teacher-student relationship. This study has shown that teachers can provide good emotional supports for students in cases of difficulty, and this, in turn, can lower students' level of statistical anxiety. On the other hand, if teachers do not appreciate their students' problems particularly their lack of statistical background, students will be more fearful and thus avoid asking for help. Consequently, asking for help anxiety can be unconsciously increased.

All in all, this study contributes to our understanding of the areas of statistics in which TEFL postgraduate students may experience anxiety and have deficiencies. The insights gained from this study may be of assistance to statistics teachers, test developers, and policy makers who, to a lesser or greater extent, have roles in helping students manage their anxiety. Moreover, insights from this descriptive work may be of interest to researchers since several questions, as mentioned earlier, still remain unanswered. The most important limitation lies in the fact that this research was mainly descriptive and did not aim to investigate the effectiveness of an intervention between different groups of students. Future investigations can take the concerns drawn from this study into account and attempt to focus more specifically on them.

\section{The Research and Publication Ethics Statement}

The Ethics Committee/Board approval for this study was obtained from Hakim Sabzevari University Ethics Committee, Sabzevar/Iran on 15/01/2020 by No 139985 . No ethical considerations were violated in this study. 


\section{The Conflict of Interest Statement}

In line with the statement of Committee on Publication Ethics (COPE), we hereby declare that we had no conflicting interests regarding any parties of this study. Also, this is an original study, and it is not funded.

\section{References}

Ary, D., Jacobs, L. C., Irvine, C.K.S., \& Walker, D. A. (2013). Introduction to research in education. Wadsworth: Cengage Learning.

Baloğlu, M. (2003). Individual differences in statistics anxiety among college students. Personality and Individual Differences, 34(5), 855-865.

Baloğlu, M. (2004). Statistics anxiety and mathematics anxiety: Some interesting differences. Educational Research Quarterly, 27(3), 38-48.

Baloğlu, M., Deniz, M. E., \& Kesici, Ş. (2011). A descriptive study of individual and crosscultural differences in statistics anxiety. Learning and Individual Differences, 21(4), 387391. https://doi.org/10.1016/j.lindif.2011.03.003

Bell, J. A. (2003). Statistics anxiety: The nontraditional student. Education, 124(1), 157-163.

Bell, J.A. (2005). Length of term and levels of statistics anxiety: A comparison of types of offerings. Academy of Information and Management Sciences Journal, 8(1), 103-108.

Benson, J. (1989). Structural components of statistical test anxiety in adults: An exploratory model. Journal of Experimental Education, 57, 247-261.

Benson, J., \& Bandalos, D. (1989). Structural model of statistical test anxiety. In R. Schwarzer, H.M. van der Ploeg, \& C.D. Spielberger (Eds.), Advances in test anxiety research (vol. 5) (pp. 207-211). Lisse: Swets and Zeitlinger: Hillsdale, N.J. Erlbaum.

Blalock, H.M. (1987). Some general goals in teaching statistics. Teaching Sociology, 15, 164172.

Bridges, G.S., Gillmore, G. M., Pershing, J. L., \& Bates, K. A. (1998). Teaching quantitative research methods: A quasi-experimental analysis. Teaching Sociology, 26(1), 14-28.

Bui, N. H., \& Alfaro, M. A. (2011). Statistics anxiety and science attitudes: Age, gender, and ethnicity factors. College Student Journal, 45(3), 573-585.

Caine, R.D., Centa, D., Doroff, C., Horowitz, J.H., \& Wisenbaker, V. (1978). Statistics from who? Teaching Sociology, 6, 37-46.

Comanaru, R.S. (2014). Essential statistics for applied linguistics. International Journal of Bilingual Education and Bilingualism, 17(4), 498-500. DOI: 10.1080/13670050.2013.809910

Cruise, R.J., Cash, R.W., \& Botlon, D.L. (1985). Development and validation of an instrument to measure statistical anxiety. In Proceedings of the American Statistical Association. Paper presented at the annual meeting of the Statistical Education Section. Chicago, IL, pp. 9297.

Cunnings, I. (2012). An overview of mixed-effects statistical models for second language researchers. Second Language Research, 28, 369-382. doi:10.1177/ 0267658312443651

DeVaney, T. A. (2017). Anxiety and attitude of graduate students in on-campus vs. online statistics courses. Journal of Statistics Education, 18(1). doi.org/10.1080/10691898.2010.11889472

Dörnyei, Z. (2007). Research methods in applied linguistics: Quantitative, qualitative, and mixed methodologies. Oxford: Oxford University Press. 
Druggeri, K., Dempster, M., Hanna, D., \& Cleary, C. (2008). Experiences and expectations: The real reason nobody likes stats. Psychology Teaching Review, 14(2), 75-83.

Fitzgerald, S.M., Jurs, S. \& Hudson, L.M., (1996). A model predicting statistics achievement among graduate students. College Student Journal, 30, 361-366.

Gaydosh, L.R. (1990). Syllabi and instructional materials for social statistics. Washington, DC: American Sociological Association.

Gonulal, T., Loewen, S., \& Plonsky, L. (2017). The development of statistical literacy in applied linguistics graduate students. ITL - International Journal of Applied Linguistics, 168(1), 432. https://doi.org/10.1075/itl.168.1.01gon

Gorard, S. (2015). Rethinking "quantitative" methods and the development of new researchers. Review of Education, 3(1), 72-96. https://doi.org/10.1002/rev3.3041

Hsiao, T., \& Chiang, S. (2011). Gender differences in statistics anxiety among graduate students learning English as a foreign language. Social Behavior and Personality, 39(1), $41-42$.

Huns ley, J.D. (1987). Cognitive processes in mathematics anxiety and test anxiety: The role of appraisals, internal dialogue, and attributions. Journal of Educational Psychology, 79, 388392.

Jones, B. D., Wilkins, J. L. M., Long, M. H., \& Wang, F. (2011). Testing a motivational model of achievement: How students' mathematical beliefs and interests are related to their achievement. European Journal of Psychology of Education, 27(1), 1-20. https://doi.org/10.1007/s10212-011-0062-9

Krapp, A. (2005). Basic needs and the development of interest and intrinsic motivational orientations. Learning and Instruction, 15, 381-395.

Khany, R., \& Tazik, K. (2019). Levels of statistical use in applied linguistics research articles: From 1986 to 2015. Journal of Quantitative Linguistics, 26(1), 48-65. https://doi.org/10.1080/09296174.2017.1421498

Lazaraton, A. (2000). Current trends in research methodology and statistics in applied linguistics. TESOL Quarterly, 34(1), 175-181. https://doi.org/10.2307/3588103

Lazaraton, A. (2005). Quantitative research methods. In E. Hinkel (Ed.), Handbook of research in second language learning (pp. 209-224). Mahwah, NJ: Lawrence Erlbaum.

Lazaraton, A., Riggenbach, H., \& Ediger, A. (1987). Forming a discipline: Applied linguists' literacy in research methodology and statistics. TESOL Quarterly, 21(2), 263-277. https://doi.org/10.2307/3586735

Lindstromberg, S. (2016). Inferential statistics in language teaching research: A review and ways forward. Language Teaching Research, 20(6), 741-768. https://doi.org/10.1177\%2F1362168816649979

Loewen, S., \& Gass, S. (2009). The use of statistics in L2 acquisition research. Language Teaching, 42(2), 181-196. doi:10.1017/S0261444808005624

Loewen, S., Lavolette, E., Spino, L. A., Papi, M., Schmidtke, J., Sterling, S., \& Wolff, D. (2014). Statistical literacy among applied linguists and second language acquisition researchers. TESOL Quarterly, 48(2), 360-388. https://doi.org/10.1002/tesq.128

Loewen, S., Gönülal, T., Isbell, D. R., Ballard, L., Crowther, D., Lim, J., Maloney, J., \& Tigchelaar, M. (2019). How knowledgeable are applied linguistics and SLA researchers about basic statistics?: data from north America and Europe. Studies in Second Language Acquisition, 42(4) 871-890. doi:10.1017/S0272263119000548

Lundgren, T.D., \& Fawcett, R. (1980). Statistics from statisticians. Teaching Sociology, 7, 191201.

Malik, S., (2015). Undergraduates' statistics anxiety: A phenomenological study. The Qualitative Report, 20(2), 120-133. 
Macher, D., Papousek, I., Ruggeri, K., \& Paechter, M. (2015). Statistics anxiety and performance: blessings in disguise. Frontiers in psychology, 6, 1116. https://doi.org/10.3389/fpsyg.2015.01116

Morris, L.W., Kellaway, D.S., \& Smith, D.H. (1978). Mathematics anxiety rating scale: Predicting anxiety experiences and academic performance in two groups of students. Journal of Educational Psychology, 70, 589-594.

Onwuegbuzie, A. J. (1997). Writing a research proposal: The role of library anxiety, statistics anxiety, and composition anxiety. Library \& Information Science Research 19, 5-33.

Onwuegbuzie, A. J. (2004). Academic procrastination and statistics anxiety. Assessment \& Evaluation in Higher Education, 29, 3-19.

Onwuegbuzie, A.J., \& Seaman, M.A., (1995). The effect of time constraints and statistics test anxiety on test performance in a statistics course. The Journal of Experimental Education, $63(2), 115-124$.

Onwuegbuzie, A.J., \& Daley, C.E. (1999). Perfectionism and statistics anxiety. Personality and Individual Differences, 26, 1089-1102.

Onwuegbuzie, A.J., \& Wilson, V.A., (2003). Statistics anxiety: Nature, etiology, antecedents, effects, and treatments-a comprehensive review of the literature. Teaching in Higher Education, 8(2), 195-209.

Onwuegbuzie, A.J. Leech, N. L., Murtonen, M., \& Tähtinen, J. (2010). Utilizing mixed methods in teaching environments to reduce statistics anxiety. International Journal of Multiple Research Approaches, 4(1), 28-39.

Payne, G., \& Williams, M. (2011). Teaching quantitative methods: Getting the basics right. Los Angeles, Calif: SAGE Publications Ltd.

Pica, S. (2003). Second language acquisition research and applied linguistics. Working Papers in Educational Linguistics, 18(2), 1-26.

Pintrich, P., \& DeGroot, E. (1990). Motivational and self-regulated learning components of classroom academic performance. Journal of Educational Psychology, 82, 33-40.

Plonsky, L. (2013). Study quality in SLA: An assessment of designs, analyses, and reporting practices in quantitative L2 research. Studies in Second Language Acquisition, 35(4), 655687.

Plonsky, L., \& Gass, S. (2011). Quantitative research methods, study quality, and outcomes: The case of interaction research. Language Learning, 61, 325-366. doi:10.1111/j.14679922.2011.00640.x

Roberts, D.M., \& Bilderback, E.W. (1980). Reliability and validity of a statistics attitude survey. Educational and Psychological Measurement, 40, 235-238.

Rodarte-Luna, B., \& Sherry, A. (2008). Sex differences in the relation between statistics anxiety and cognitive/learning strategies. Contemporary Educational Psychology, 33(2), 327-344. https://doi.org/10.1016/j.cedpsych.2007.03.002

Schacht, S., \& Stewart, B.J. (1991). What's funny about statistics? Interactive/user-friendly gimmicks for teaching statistics. Teaching Sociology, 20, 329-332.

Scholfield, P. (1991). Statistics in linguistics. Annual Review of Anthropology, 20(1), 377-393.

Sutarso, T. (1992). Some variables in relation to students' anxiety in learning statistics. Paper presented at the annual meeting of the Mid-South Educational Research Association, Knoxville, TN.

Trimarco, K.A. (1997, October). The effects of a graduate learning experience on anxiety, achievement, and expectations in research and statistics. Paper presented at the annual meeting of the Northeastern Educational Research Association, Memphis, TN. 
Vigil-Colet, A., Lorenzo-Seva, U., \& Condon, L. (2008). Development and validation of the statistical anxiety scale. Psicothema, 20(1), 174- 180.

Williams, M., Sloan, L., Cheung, S. Y., Sutton, C., Stevens, S. \& Runham, L. (2015). Can't Count or Won't Count? Embedding Quantitative Methods in Substantive Sociology

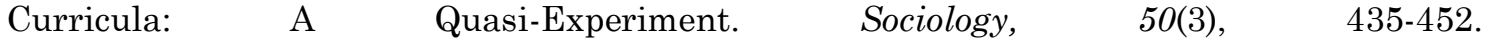
https://doi.org/10.1177\%2F0038038515587652

Zeidner, M. (1990). Does test anxiety bias scholastic aptitude test performance by gender and sociocultural group? Journal of Genetical Psychology, 150, 175-185.

Zeidner, M. (1991). Statistics and mathematics anxiety in social science students -some interesting parallels. British Journal of Educational Psychology, 61, 319-328.

\section{Appendix A. Statistical anxiety scale}

\begin{tabular}{|l|l|}
\hline Full name & \\
\hline Age & \\
\hline Gender & \\
\hline
\end{tabular}

Purpose: The purpose of this questionnaire is to assess the anxiety encountered when taking a statistics course by TEFL postgraduate students. Each item is a positive sentence that describes a typical situation that you can experience. You can indicate your level of anxiety in such a situation using a five-point scale ranging from $<<$ no anxiety $>>(1)$ to $<<$ considerable anxiety $>>(5)$.

Confidentiality: Please note that the responses you provide are completely anonymous and confidential. The research outcome and report will not include reference to any individuals.

\section{PLEASE CIRCLE THE RESPONSE THAT REPRESENTS YOUR LEVEL OF ANXIETY}

\section{Studying for an examination in a statistics course.}

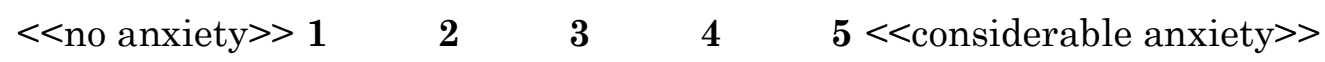

2. Interpreting the meaning of a table in a journal article.

$\begin{array}{lllll}1 & 2 & 3 & 4 & 5\end{array}$

3. Going to ask my statistics teacher for individual help with material I am having difficulty understanding.

$\begin{array}{lllll}1 & 2 & 3 & 4 & 5\end{array}$


4. Realizing the day before an exam that I cannot do some problems that I thought were going to be easy.

$$
\begin{array}{llllll}
1 & 2 & 3 & 4 & 5
\end{array}
$$

5. Asking a private teacher to explain a topic that I have not understood at all.

$$
\begin{array}{lllll}
1 & 2 & 3 & 4 & 5
\end{array}
$$

6. Reading a journal article that includes some statistical analyses.

$\begin{array}{lllll}1 & 2 & 3 & 4 & 5\end{array}$

7. Asking the teacher how to use a probability table.

$\begin{array}{lllll}1 & 2 & 3 & 4 & 5\end{array}$

8. Trying to understand a mathematical demonstration.

$\begin{array}{llllll}1 & 2 & 3 & 4 & 5\end{array}$

9. Doing the final examination in a statistics course.

$\begin{array}{lllll}1 & 2 & 3 & 4 & 5\end{array}$

10. Reading an advertisement for an automobile which includes figures on gas mileage, compliance with population regulations, etc.

$\begin{array}{llllll}1 & 2 & 3 & 4 & 5\end{array}$

11. Walking into the classroom to take a statistics test.

$\begin{array}{lllll}1 & 2 & 3 & 4 & 5\end{array}$

12. Asking the teacher about how to do an exercise.

$\begin{array}{lllll}1 & 2 & 3 & 4 & 5\end{array}$

13. Getting to the day before an exam without having had time to revise the syllabus.

$\begin{array}{lllll}1 & 2 & 3 & 4 & 5\end{array}$

14. Waking up in the morning on the day of a statistics test.

$\begin{array}{llllll}1 & 2 & 3 & 4 & 5\end{array}$

15. Realizing, just before you go into the exam, that I have not prepared a particular exercise.

$\begin{array}{lllll}1 & 2 & 3 & 4 & 5\end{array}$


16. Copying a mathematical demonstration from the blackboard while the teacher is explaining it.

$$
\begin{array}{lllll}
1 & 2 & 3 & 4 & 5
\end{array}
$$

17. Asking one of your teachers for help in understanding a printout.

$$
\begin{array}{llllll}
1 & 2 & 3 & 4 & 5
\end{array}
$$

18. Trying to understand the odds in a lottery.

$$
\begin{array}{lllll}
1 & 2 & 3 & 4 & 5
\end{array}
$$

19. Seeing a classmate carefully studying the results table of a problem he has solved.

$$
\begin{array}{lllll}
1 & 2 & 3 & 4 & 5
\end{array}
$$

20. Going to a statistics exam without having had enough time to revise.

$$
\begin{array}{lllll}
1 & 2 & 3 & 4 & 5
\end{array}
$$

21. Asking a teacher for help when trying to interpret a results table.

$$
\begin{array}{lllll}
1 & 2 & 3 & 4 & 5
\end{array}
$$

22. Trying to understand the statistical analyses described in the abstract of a journal article.

$$
\begin{array}{llllll}
1 & 2 & 3 & 4 & 5
\end{array}
$$

23. Going to the teacher's office to ask questions.

$$
\begin{array}{lllll}
1 & 2 & 3 & 4 & 5
\end{array}
$$

24. Asking a private teacher to tell me how to do an exercise.

$\begin{array}{lllll}1 & 2 & 3 & 4 & 5\end{array}$

\section{Copyrights}

Copyright for this article is retained by the author(s), with first publication rights granted to the Journal. This is an open-access article distributed under the terms and conditions of the Creative Commons Attribution license (CC BY-NC-ND) (http://creativecommons.org/licenses/by-nc-nd/4.0/). 